\title{
Blind method regarding the effect of dexmedetomidine on CRBD
}

\author{
Bailong Hu${ }^{1}$ (1) $\cdot$ Haiyan $\mathrm{Zhou}^{2} \cdot$ Xiaohua Zou $^{1}$
}

Received: 19 February 2018 / Accepted: 12 April 2018 / Published online: 26 April 2018

(c) Japanese Society of Anesthesiologists 2018

To the Editor:

We have read an article written by Kwon et al. with great interest [1]. It is a welcome investigation which evaluated the effect of the intraoperative dexmedetomidine (DEX) on the incidence and severity of catheter-related bladder discomfort (CRBD) after nonurologic surgery. We agree with their conclusion that DEX may have benefits in preventing CRBD after lumbar microdiscectomy. However, we have a question regarding the blind method.

In this article, the author stated that DEX was infused at a loading dose of $1 \mu \mathrm{g} / \mathrm{kg}$ over $10 \mathrm{~min}$, followed by a continuous infusion of $0.3-0.5 \mu \mathrm{g} / \mathrm{kg} / \mathrm{h}$, the dose of which is adjusted by the operator based on blood pressure, heart rate, and BIS values in group D (experimental group), while an identical volume of $0.9 \%$ saline was infused in the same manner in the group C (control group). According to the author's description, the operator was aware of both groups for each individual. In other words, the operator was not blinded, which may cause the possibility of observation bias. We suggest that the study drugs (DEX $200 \mu \mathrm{g} / 2 \mathrm{~mL}$ and normal saline $2 \mathrm{~mL}$ ) should be diluted into the same syringe with normal saline to $50 \mathrm{~mL}$, and infused at a loading rate of $0.25 \mathrm{~mL} / \mathrm{kg}$ over $10 \mathrm{~min}$, followed by a continuous infusion of $0.075-0.125 \mathrm{~mL} / \mathrm{kg} / \mathrm{h}$ according to the study of Su et al [2], but not at the dose of DEX $(\mu \mathrm{g} / \mathrm{kg} / \mathrm{h})$, so that the operator is blinded to the group allocation.

\section{Compliance with Ethical Standards}

Conflict of interest None declared.

\section{References}

1. Kwon Y, Jang JS, Hwang SM, Lee JJ, Tark H. Intraoperative administration of dexmedetomidine reduced the postoperative catheter-related bladder discomfort and pain in patients undergoing lumbar microdiscectomy[J]. Journal Anesth. 2017:1-7.

2. Su X, Meng ZT, Wu XH, Cui F, Li HL, Wang DX, Zhu X, Zhu SN, Maze M, Ma D. Dexmedetomidine for prevention of delirium in elderly patients after non-cardiac surgery: a randomised, double-blind, placebo-controlled trial[J]. Lancet. 2016;388(10054):1893-902.
Bailong Hu, Haiyan Zhou and Xiaohua Zou contributed equally to the letter.

This comment refers to the article available at: https://doi. org/10.1007/s00540-017-2425-0.

Bailong $\mathrm{Hu}$

375896605@qq.com

1 Department of Anesthesiology, The Affiliated Hospital of Guizhou Medical University, No. 28 Guiyi Street, Yunyan District, 550004 Guiyang, China

2

\footnotetext{
Department of Clinical Research Centre, The Affiliated Hospital of Guizhou Medical University, No. 28 Guiyi Street, Yunyan District, 550004 Guiyang, China
} 